\section{ESTUDO DA DISCIPLINA DE LIBRAS EM DUAS \\ LICENCIATURAS NO LITORAL DO PARANÁ}

Érica Alves Fernandes de Andrade
THE STUDY OF LIBRAS DISCIPLINE IN TWO

TEACHER EDUCATION COURSES IN PARANÁ COAST

\section{Resumo}

Esta pesquisa se reporta aos resultados sobre as reflexões dos estudantes de duas licenciaturas da Universidade Estadual do Paraná, campus Paranaguá, sobre a Língua Brasileira de Sinais, em relação ao conhecimento prévio dessa, à carga horária ministrada, às dificuldades e mudanças de paradigmas com relação ao mundo surdo. Os dados foram sistematizados a partir de um questionário com seis perguntas fechadas, com o objetivo de pesquisar a oferta da disciplina da Língua Brasileira de Sinais no curso de Pedagogia e Letras, investigando a visão dos licenciandos e do professor sobre os limites e possibilidades da carga horária e dos objetivos do ementário sugerido, tendo como parâmetro os pressupostos da educação bilíngue discutidos pelas pesquisadoras Dorziat (2009), Felipe (2007), Martins (2011), Mercado (2012), Quadro; Karnopp (2004), Quadros; Schimiedt (2006), Stroebel (2008), Stroebel (2011) e Witkoski (2012) e por Skliar (2011). O produto contribuirá para um (re)pensar na formação de docentes no exercício futuro da função.

Palavras-chave: Formação de docentes, Educação bilíngue, Libras.

\section{Abstract}

The research presents the results of teacher education students' reflections from two courses in Paraná State University, Paranaguá campus, on Brazilian Sign Language, their background knowledge, the course load, the difficulties and paradigm changes related to the deaf world. The data were organized from a questionnaire with six closed questions aiming to research the offer of the Brazilian Sign Language discipline in the Education and Languages courses to investigate the teacher-students and professor's view on the limits and possibilities of the course load and the goals suggested in the discipline program, taking as a parameter the bilingual education basis argued by the researchers Dorziat (2009), Felipe (2007), Martins (2011), Mercado (2012), Quadros; Karnopp (2004), Quadros; Schimidt (2006), Stroebel (2008), Stroebel (2011) and Witkoski (2012) and by Skliar (2011). It is expected that the results may contribute to a (re)thinking of teacher education towards the future of these professionals.

Keywords: teacher education, bilingual education, Brazilian Sign Language.

1 - Especialista em Educação Especial (DA-DM-DV), em Gestão Educacional e em Educação Bilíngue Para Surdos - Libras/ Língua Portuguesa.

Professora do Quadro Próprio do Magistério da Secretaria de Estado da Educação do Paraná SEED. 41 - 9909-9762/ 3473-3869 - ericadeandrade@gmail.com

Orientadora: Neide Mitiyo Shimazaki Tsukamoto 


\section{Introdução}

A Lei $n^{\circ}$ 10.436/2002 reconhece a Língua Brasileira de Sinais - Libras, como língua de uso legítimo e corrente de uma grande parcela de surdos brasileiros, assim como a inclusão da disciplina de Libras como parte integrante do currículo nos cursos de formação de professores e de fonoaudiologia. (MEC/ SEESP, 2008).

Esta Lei, regulamentada pelo Decreto $\mathrm{n}^{\circ}$ 5.626/2005, torna a Libras disciplina obrigatória nos cursos de licenciatura e fonoaudiologia, incluindo-a nos currículos da Educação Básica para Surdos nas escolas de Surdos (Idem, 2008), além de oferecer maior organização à educação da comunidade surda.

Entretanto, apesar dos prazos estipulados para a execução da referida legislação (até 2015), ainda percebe-se uma morosidade e/ou cumprimento meramente procedimental da lei que se esperava promover ações inclusivas do grupo social em pauta. Mas a que/quem poderse-ia atribuir essa responsabilidade?

Ao longo da última década, a participação da comunidade linguística surda empreendeu esforços hercúleos a fim de ter seus direitos reconhecidos e garantidos, após anos de invisibilidade social, por meio da atuação política e produção acadêmica. No entanto, mesmo após protagonizar a elaboração do Programa Nacional de Apoio à Educação de Surdos em 2001, tanto as políticas públicas capitaneadas pelo Ministério da Educação (MEC) quanto o âmbito legislativo federal restringiram a continuidade de políticas públicas voltadas à perspectiva da educação bilíngue. Assim, apesar de haver mecanismos legais para os surdos, a concepção desses mecanismos originou-se sem a participação dos principais interessados, potencializando a continuidade da exclusão velada, desta vez amparada e escamoteada pelo decreto.
Frente a este viés, o presente projeto objetiva a pesquisar a oferta da disciplina de Libras em cursos de licenciatura e investigar a visão dos estudantes e do professor sobre os limites e possibilidades da carga horária e dos objetivos do ementário proposto, tendo como parâmetro os pressupostos da educação bilíngue. O campo escolhido para a pesquisa é a Faculdade Estadual de Filosofia, Ciências e Letras de Paranaguá, que tem em seu rol de cursos ofertados as seguintes licenciaturas: Ciências Biológicas, História, Matemática, Pedagogia e Letras, constituindo os dois últimos o nosso objeto de estudo.

Os resultados desse trabalho poderão ser utilizados pelas IES no sentido de (re)pensar pedagogicamente nos cursos de licenciatura, no sentido de preparar os futuros docentes para o exercício do magistério, considerando a presença de discentes surdos em sala de aula.

Percebeu-se a necessidade de aprofundar estudos na questão da oferta da disciplina de Libras em Licenciaturas ao analisar a carga horária expressa no conteúdo programático dos referidos cursos, cuja ementa ${ }^{2}$ se encerra nestes termos (vide anexo):

Esta disciplina objetiva desenvolver as habilidades necessárias para a aquisição da LIBRAS - a língua de modalidade visual e gestual das pessoas surdas. Abrange os conteúdos gerais para comunicação visual, baseada em regras gramaticais da Língua de Sinais e da Identidade e Cultura Surda.

Assim, buscamos fazer a leitura do que a disciplina de Libras está proporcionando aos estudantes nas licenciaturas da instituição em foco, se é vista como relevante por eles e se a carga horária ministrada nos cursos de Pedagogia e Letras Português/ Inglês é suficiente para preparar ou formar professores para a educação de surdos.

2 - Embora o texto se refira ao ano civil de 2009 e ao curso de Pedagogia, os conteúdos se aplicam a 2013 para todas as licenciaturas da referida IES. 
Quadros e Karnopp (2004, p. 24-25) fazem uma breve revisão da literatura e encontram definições de língua, a partir de Saussure (1995), Bloch e Trager (1942), Hall (1968) e Robins (1979). As autoras mostram a visão de Saussure (1995, p. 17) quanto à concepção de língua: "É, ao mesmo tempo, um produto social da faculdade de linguagem e um conjunto de convenções necessárias, adotadas pelo corpo social para permitir o exercício dessa faculdade nos indivíduos". Complementam com a definição de Bloch e Trager (1942, p. 5) "uma língua é um sistema de símbolos vocais arbitrários por meio do qual um grupo social co-opera". Hall (1968, p. 158) também é citado por ambas quando afirma que a língua(gem) "é a instituição pela qual os humanos se comunicam e interagem uns com os outros por meio de símbolos arbitrários orais-auditivos habitualmente utilizados".

Ainda em Quadros e Karnopp (Idem, p. 24-25), percebemos que as definições de Bloch e Trager (1942) e Hall (1968) dirigem-se somente às línguas orais e Robins (1979, p. 9-14), também comentado pelas autoras, faz uma discussão que engloba qualquer teoria da linguagem e afirma que as línguas são sistemas de símbolos que se baseiam praticamente em convenções puras ou arbitrárias, elucidando a flexibilidade e adaptabilidade que esses sistemas podem ter.

Quadros e Karnopp (2004, p. 25) também se pautam em autores como Hockett (1992, p. 11-20), Lyons (1981, p. 30-5) e Lobato (1986, p. 41-7) para descrever uma lista de traços atribuídos às línguas em geral, os quais apontam divergências entre língua e sistemas de comunicação animal.

Para melhor visualização, ilustraremos no quadro a seguir:

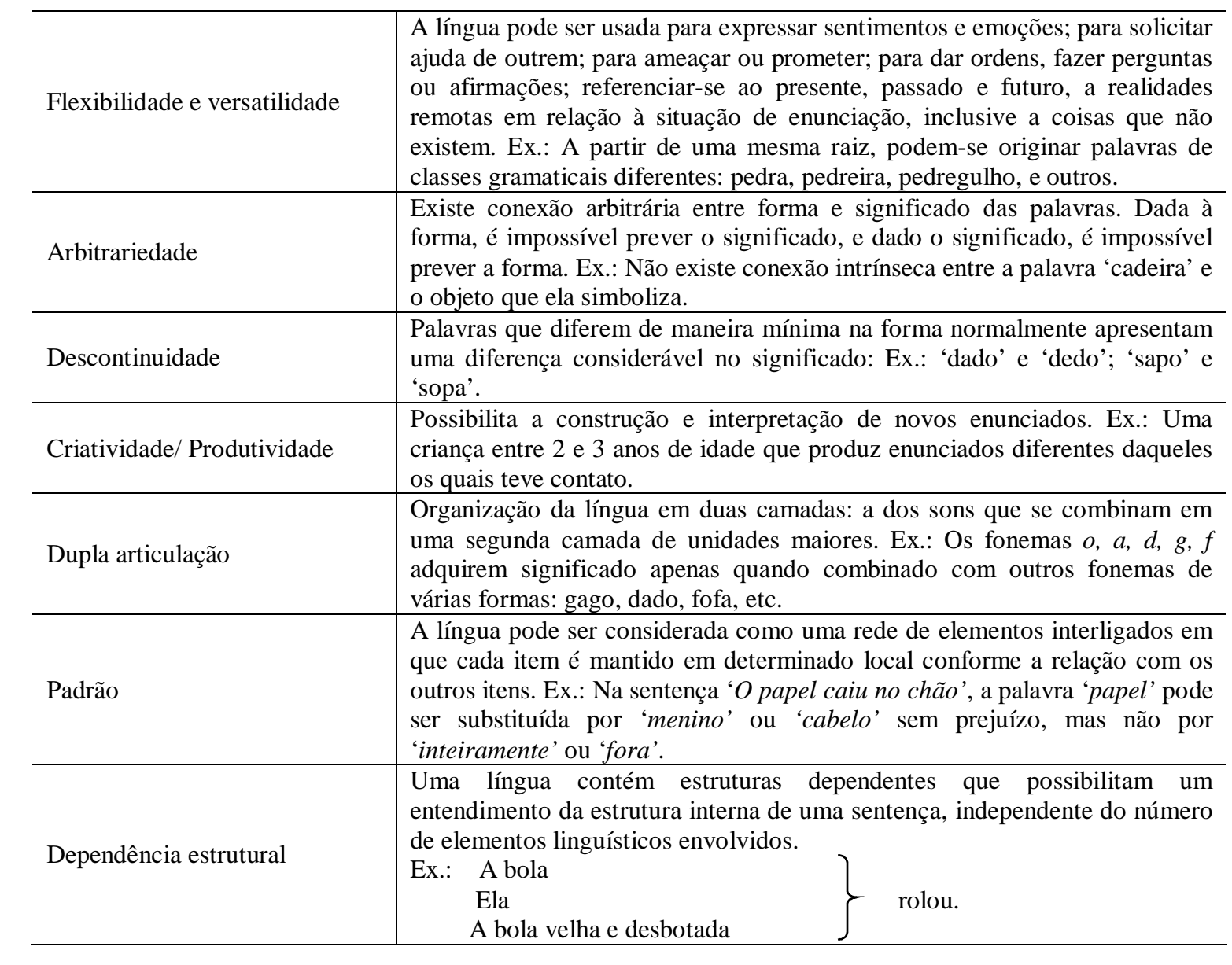

Tabela 1 - Traços atribuídos às línguas

Fonte: Quadros e Karnopp (2004, p. 25-28). Tabela sistematizada pela autora. 
Quadros e Karnopp (2004, p. 24) destacam que a modalidade de percepção e produção da língua produzida pelos seres humanos pode ser oral-auditiva ou visuoespacial.

Exemplificamos a modalidade oral-auditiva com o português, espanhol, inglês, etc. Deteremos-nos na outra modalidade, a visuoespacial, que pode ser a Língua Brasileira de Sinais - Libras, Língua de Sinais Americana - ASL, Língua de Sinais Francesa - ASF, dentre outras.

Fernandes (2011, p. 79) destaca nos seus escritos que a língua de sinais, utilizada pelas pessoas surdas, oferece os elementos simbólicos essenciais ao desenvolvimento das funções psíquicas superiores, como o pensamento, a memória, a formação e a generalização de conceitos, e outros.

A pesquisadora (Idem, p. 80) esclarece que encontramos registros de que desde os primórdios, já na Antiguidade, se mencionava sobre a comunicação diferenciada entre os surdos. Embora essa forma de comunicar-se seja de longa data, somente em tempos recentes é que estudos estão sendo realizados na área.

\section{Libras no contexto legal}

Como cada país tem seu próprio idioma, a Libras é a língua utilizada pela comunidade de surdos do Brasil. ${ }^{3}$ É reconhecida e ratificada em território nacional pela Lei no 10.436, de 24 de abril de 2002, significando uma conquista da comunidade, sendo que elencamos alguns artigos:

Art. $\mathbf{1}^{0}$. É reconhecida como meio legal de comunicação e expressão a Língua Brasileira de Sinais - Libras e outros recursos de expressão a ela associados.

Parágrafo único. Entende-se como Língua Brasileira de Sinais - Libras a forma de comunicação e expressão, em que o sistema linguístico de natureza visual-motora, com estrutura gramatical própria, constituem um sistema linguístico de transmissão de ideias e fatos, oriundos de comunidades de pessoas surdas do Brasil.

(...)

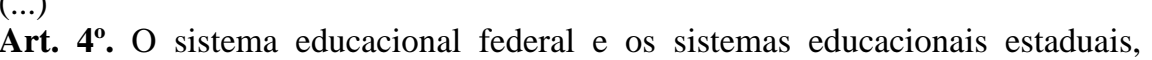

municipais e do Distrito Federal devem garantir a inclusão nos cursos de formação de Educação Especial, de Fonoaudiologia e de Magistério, em seus níveis médio e superior, do ensino da Lingua Brasileira de Sinais - Libras, como parte integrante dos Parâmetros Curriculares Nacionais - PCNs, conforme legislação vigente. (Grifo nosso).

Em 22 de dezembro de 2005, o Decreto Federal $n^{\circ}$ 5.626/2005 foi sancionado e regulamenta a lei de 2002 (BRASIL, 2005). Um dos destaques que se pode verificar na legislação de 2005, na esfera educacional, é a consideração de que os surdos vivem em um país cuja maioria linguística é diferente da sua, portanto deveriam ser preparados sob uma perspectiva bilíngue.

Mercado (2012, p. 59) aponta que o decreto trouxe "uma nova perspectiva para o atendimento da comunidade surda brasileira, no que se refere à efetivação do acesso dessa comunidade a todos os âmbitos da sociedade em que se encontra inserida, inclusive no setor educacional.".

Indiscutivelmente, a regulamentação abriu portas e contribuiu para que o sujeito surdo fosse interpretado de outra maneira. Segundo Fernandes (2011, p. 81), um fato de suma importância foi a inclusão da Libras como disciplina curricular obrigatória nos cursos de licenciaturas, em nível médio e superior, e de Fonoaudiologia, "pois prepara o futuro educador para a reflexão sobre formas alternativas de comunicação e de interação como requisito de acesso aos conteúdos acadêmicos."

Entendemos que em qualquer processo de formação, seja inicial ou continuada, é necessário prover professores e licenciandos com conhecimento na área de educação bilíngue para a melhoria dos processos educacionais ministrados a alunos surdos na rede comum de ensino, em escolas comuns para surdos, em turmas em que a Libras é língua de instrução, ou em 3 - Na comunidade surda, o sujeito surdo é tido como aquele que faz uso da língua de sinais, que luta para ter seus direitos de cidadania e linguísticos respeitados, apreende o mundo de forma diferenciada e seus comportamentos e valores são compartilhados e as tradições sócio-interativas são transmitidas entre seus pares. (FELIPE, 2007, p. 45). 
sala de recursos. (QUADROS; SCHMIEDT, 2006,p. 9).

No entanto, é necessário ter um olhar crítico sobre como as legislações são observadas no Brasil. Witkoski (2012, p. 18) nos alerta que "apenas o reconhecimento legal não é suficiente para alterar as concepções preconceituosas em relação à Língua de Sinais (...)" pois a Libras ainda não desfruta do mesmo prestígio linguístico que as línguas orais, sendo considerada por alguns como uma mescla de gesticulação concreta e pantomima. Portanto, há que contextualizar a trajetória da educação para os surdos para compreender suas demandas.

Em maio de 2011 a Revista Setembro Azul publicou um manifesto enviado ao Ministro da Educação da República Federativa do Brasil da época, Sr. Dr. Fernando Haddad, em nome da Comunidade Surda Brasileira. O documento exprime o posicionamento da comunidade surda perante a desconsideração de suas contribuições para a construção de propostas legislativas para a educação bilíngue. (STROEBEL, 2011).

A presente investigação, no intuito de obter dados empíricos, aplicou questionário aos estudantes, cujos resultados serão discutidos na sequência.

\section{A pesquisa: alguns dados}

A primeira opção seria investigar a estrutura curricular (disciplina de Libras) dos cursos de formação de docentes no Campus da Universidade Federal do Paraná, sediado em Matinhos/PR (UFPR - Setor Litoral).

Por conta da greve nacional dos docentes federais, deflagrada em meados de maio de 2012 e encerrada em setembro do mesmo ano, não foi possível executar a primeira opção de campo. Assim, optou-se por deslocar a entrevista para a Universidade Estadual do Paraná (UNESPAR) campus Paranaguá, pelo fato de já ter contato com o professor (surdo) de Libras da Instituição. Assim, empreendeu-se a pesquisa de campo entre discentes de algumas licenciaturas (Pedagogia e Letras - Português/Inglês) dessa última IES

Empregou-se o uso do questionário como instrumento para a construção dos dados. A investigação contou com seis perguntas fechadas de múltipla escolha, as quais visavam às opiniões dos estudantes sobre Libras, do seu conhecimento prévio da língua de sinais antes da graduação, da carga horária, do olhar sobre mundo surdo, quanto às suas competências para mediar conteúdos para estudantes surdos e qual sua consideração sobre Libras.

As participações nos questionários respondidos e devolvidos equivalem a 26 estudantes, sendo que 46,1\% eram do curso de Pedagogia, 46,1\% de Letras - Português/Inglês e 7,6\% não se identificaram.

Salientamos que estudos focados na formação de professores na área da educação inclusiva também podem ser encontrados em outras pesquisas, como em Martins (2011), que descreve sobre a atuação dos docentes com a diversidade dos alunos, no exercício futuro da profissão, e em Mercado (2012), problematizando a inclusão do surdo na rede comum de ensino.

Com o intuito de facilitar a visualização, os resultados dos questionários e suas respectivas análises serão aduzidos, a seguir, em 6 tabelas, constando uma pergunta de múltipla escolha, o universo e número de participação dos alunos.

Os resultados da questão 1. Sobre a Língua Brasileira de Sinais - Libras; 34,6\% do Curso de Letras, $42,3 \%$ de Pedagogia e 3,8\% dos não identificados responderam que não tinham conhecimento prévio de Libras antes da graduação, enquanto 11,5\% de Letras e 3,8\% de Pedagogia conheciam alguns sinais usuais. Já os 3,8\% tinham conhecimento suficiente para interagir em Libras. Não houve resposta para a alternativa $D$, que indagava sobre a fluência do aluno. A participação foi de $100 \%$ na questão.

4 - A UFPR - Setor Litoral oferta três licenciaturas: Artes, Ciências e Linguagem e Comunicação. Informações obtidas na página http://www.litoral.ufpr.br/grad.

5 - Acontecimento este que refletiu no cumprimento do calendário escolar. 


\begin{tabular}{|c|c|c|c|c|}
\hline \multirow{2}{*}{$\begin{array}{c}\text { PERGUNTA } \\
\text { CURSO }\end{array}$} & \multicolumn{3}{|c|}{$\begin{array}{l}\text { 1. Sobre a Língua Brasileira de Sinais - } \\
\text { Libras. }\end{array}$} & \multirow{2}{*}{$\begin{array}{c}\text { Participações } \\
(26) \\
\text { UNIVERSO } \\
(26) \\
\end{array}$} \\
\hline & $\begin{array}{l}\text { LETRAS } \\
\text { (12) }\end{array}$ & $\begin{array}{l}\text { PEDAGOGIA } \\
\text { (12) }\end{array}$ & $\begin{array}{c}\text { NÃO } \\
\text { IDENT. (2) }\end{array}$ & \\
\hline $\begin{array}{l}\text { A Não sabia nada de Libras antes de } \\
\text { ingressar na licenciatura. }\end{array}$ & 9 & 11 & 1 & 21 \\
\hline B Sabia alguns sinais. & 3 & 1 & 0 & 4 \\
\hline $\begin{array}{l}\text { C Já conseguia me comunicar com uma } \\
\text { pessoa surda usando Libras. }\end{array}$ & 0 & 0 & 1 & 1 \\
\hline D Era fluente em Libras. & 0 & 0 & 0 & 0 \\
\hline
\end{tabular}

Tabela 2 - Opinião sobre Libras - Base de dados: 26 Fonte: A autora

Para comentarmos esta questão, faz-se necessário resgatarmos um pouco da história da educação de surdos.

Por muito tempo houve predomínio da perspectiva oralista na educação de surdos. Skliar (2001, p. 88) mostra que "a ideologia do oralismo se manteve em muitos casos intacta", ratificando também que "embora muitos já falarem de sua extinção, tem sido e continua sendo, ainda hoje, em boa parte do mundo, uma ideologia dominante na educação dos surdos.".

Felipe (2007, p. 152) explica que podemos entender por oralismo a filosofia educacional imposta na educação de surdos a partir do Congresso de Milão em 1880. Os alunos surdos foram vetados de fazerem uso da língua de sinais. Era comum que as crianças tivessem as mãos amarradas, a fim de impedi-las de fazerem sinais. Essa prática também foi adotada no Brasil, pois era entendido que o ato de sinalizar atrapalhava o desenvolvimento da oralização.

Segundo Perlin e Strobel (2008, p. 12), o método oral puro, admitia ser a única forma desejável de comunicação para o sujeito surdo, rejeitando a língua de sinais. Também afirmam que o Congresso de Milão tornou-se o evento de maior impacto na educação de surdos, refletindo significativamente na educação porque os "sujeitos surdos ficaram subjugados às práticas ouvintistas, tendo que abandonar sua cultura, a sua identidade surda e se submeteram a uma 'etnocêntrica ouvintista', tendo de imitá-los"' (Idem, 2008, p. 6).

A comunicação total surgiu no final da década de 1960 e começo dos anos 70, após o fracasso do oralismo. Privilegia qualquer forma de comunicação com a pessoa surda (gestos, língua de sinais, fala, leitura oro-facial, leitura escrita, alfabeto manual, dentre outros), desordenando e desvalorizando a hierarquia das aquisições linguísticas e, portanto, cognitivas e culturais. (SKLIAR, 2001, p. 89).

Esta modalidade "utiliza basicamente o bimodalismo, que é o emprego simultâneo de duas modalidades de comunicação: os sinais e a fala (oral)." Assim acontecendo, a língua de sinais perde suas características, moldando-se à estrutura da Língua Portuguesa. (DORZIAT, 2009, p. 48).

A educação bilíngue é uma proposta de ensino utilizada por escolas que sugerem acessar aos sujeitos surdos duas línguas no contexto escolar. Considera a língua de sinais como primeira língua e a partir daí passam para a segunda língua, que é o Português, podendo ser na modalidade oral ou escrita. Nesta ideologia, a criança surda deve ter o primeiro contato com pessoas fluentes na língua de sinais (LS), sendo elas seus pais, professores, ou outrem. (PERLIN; STROBEL, 2008, p. 15,16).

Witkoski (2012, p. 13, 42-43) considera que o ensino bilíngue para estudantes surdos, "previsto na legislação brasileira, tem como pressuposto que a língua de instrumentação seja a Libras" e reitera que a educação bilíngue respeita as singularidades da aprendizagem dos surdos e contempla a Libras como língua de instrução e o Português como segunda língua.

Embora Libras seja também uma língua oficial do Brasil, é aceitável que existam

6 - Treinamento de fala e audição (SKLIAR, 1997 apud STROBEL 2008, p. 36).

7 - O Congresso de Milão reuniu os diretores das mais renomadas escolas da Europa para surdos e propôs a extinção do gestualismo, dando lugar à palavra falada. O evento legitimou oficialmente o oralismo, sendo que o mesmo fora imposto nas escolas de surdos. (SKLIAR, 2001, p. 89). 8 - O "Ouvintismo" (SKLIAR, 1998, p. 15). Trata-se de um conjunto de representações dos ouvintes, a partir do qual o surdo está obrigado a olhar-se e narrar-se como se fosse ouvinte e reproduzir suas práticas culturais para ser aceito. 
pessoas que não tenham conhecimento dessa língua, como percebemos nas respostas dos acadêmicos pesquisados. Não podemos negar uma trajetória que foi percorrida pela humanidade, pois vivíamos num contexto de segregação.

Na questão 2, A carga horária de Libras ministrada foi suficiente para contribuir com minha formação profissional, encontramos que 15,3\% de Letras, 19,2\% de Pedagogia e 3,8\% dos não identificados disseram que a carga horária foi suficiente para contribuir com sua formação profissional, sendo que 26,9\% de Letras, 26,9\% de Pedagogia e 3,85\%dos não identificados disseram que a carga horária foi suficiente para contribuir com sua formação profissional, sendo que 26,9\% de Letras, 26,9\% de Pedagogia e 3,85\% dos não identificados discordaram. 3,8\% de Letras deixaram de responder. A participação foi de $96,15 \%$ na questão.

\begin{tabular}{c|c|c|c|c}
\hline \multirow{2}{*}{ PERGUNTA } & \multicolumn{3}{|c|}{$\begin{array}{c}\text { 2. A carga horária de Libras ministrada foi suficiente para } \\
\text { contribuir com minha formação profissional. }\end{array}$} & $\begin{array}{c}\text { Participações } \\
\text { (25) }\end{array}$ \\
\hline CURSO & LETRAS (12) & PEDAGOGIA(12) & NÃO IDENT. (2) & UNIVERSO (26) \\
\hline A.( ) Sim & 4 & 5 & 1 & 10 \\
\hline B.( ) Não & 7 & 7 & 1 & 15 \\
\hline
\end{tabular}

Tabela 3 - Opinião sobre Libras - Base de dados: 26 Fonte: A autora

Verificamos no art. 10 da Resolução CNE/CP n ${ }^{\circ}$, de 18 de Fevereiro de 2002, que institui as Diretrizes Curriculares para a Formação de Professores da Educação Básica, o seguinte:

Art. 10. A seleção e o ordenamento dos conteúdos dos diferentes âmbitos de conhecimento que comporão a matriz curricular para a formação de professores, de que trata esta Resolução, serão de competência da instituição de ensino, sendo o seu planejamento o primeiro passo para a transposição didática, que visa a transformar os conteúdos selecionados em objeto de ensino dos futuros professores.

O documento supracitado confere às IES a autonomia na sistematização dos conteúdos, os quais incorporação a matriz curricular nos cursos de licenciaturas, dando destaque à forma de planejamento dos mesmos.

Podemos reconhecer que a maioria dos acadêmicos visualiza a carga horária (68h) como insuficiente na formação inicial. O fato pode ser compartilhado nos estudos de Martins (2012, p. 59), pois a autora descreve a necessidade de mais tempo para uma continuidade e aprofundamento dos estudos, afim de que esses alunos possam aplicar-se em pesquisas, e com isso, ampliar seus horizontes.

Como o decreto 5.626/2005 não regulamenta a carga horária, o conteúdo e outros elementos os quais devem constar no plano de ensino da disciplina de Libras nas licenciaturas (MERCADO, 2012, p. 59), as IES elegem os aspectos de ensino de Libras que mais lhes convêm, resultando na discrepância entre as ementas nos diferentes cursos, o que garante um aprendizado de qualidade duvidosa.

As respostas da pergunta 3, sobre a Carga Horária de Libras ministrada apontam que 26,9\% de Letras, $15,3 \%$ de Pedagogia e 3,85\% dos não identificados compreendem que a carga horária que tiveram de Libras ofereceu condições de se comunicarem com uma pessoa surda, tendo o olhar sobre as diferenças linguísticas e culturais do mundo surdo. 3,8\% de Letras e

\begin{tabular}{|c|c|c|c|c|}
\hline PERGUNTA & \multicolumn{3}{|c|}{$\begin{array}{l}\text { 3. A carga horária de Libras } \\
\text { ministrada: }\end{array}$} & $\begin{array}{l}\text { Participações } \\
\text { (26) }\end{array}$ \\
\hline CURSO & $\begin{array}{c}\text { LETRAS } \\
\text { (12) }\end{array}$ & $\begin{array}{c}\text { PEDAGOGIA } \\
\text { (12) }\end{array}$ & $\begin{array}{c}\text { NÃO } \\
\text { IDENT. (2) } \\
\end{array}$ & UNIVERSO (26) \\
\hline $\begin{array}{l}\text { A.( ) Ofereceu condições de comunicar-me com uma } \\
\text { pessoa surda e ter olhar sobre as diferenças linguísticas e } \\
\text { culturais do mundo surdo. }\end{array}$ & 7 & 4 & 1 & 12 \\
\hline $\begin{array}{l}\text { B.( ) Ofereceu condições de comunicar-me com uma } \\
\text { pessoa surda, mas não contribuiu para que eu tivesse } \\
\text { outro olhar sobre as diferenças linguísticas e culturais do } \\
\text { mundo surdo. }\end{array}$ & 1 & 0 & 1 & 2 \\
\hline $\begin{array}{l}\text { C.( ) Não ofereceu condições de comunicar-me com uma } \\
\text { pessoa surda, mas contribuiu para que eu tivesse outro } \\
\text { olhar sobre as diferenças linguísticas e culturais do mundo } \\
\text { surdo. }\end{array}$ & 4 & 8 & 0 & 12 \\
\hline $\begin{array}{l}\text { D. ( ) Não ofereceu condições de comunicar-me com uma } \\
\text { pessoa surda, nem contribuiu para que eu tivesse outro } \\
\text { olhar sobre as diferenças linguísticas e culturais do mundo } \\
\text { surdo. }\end{array}$ & 0 & 0 & 0 & 0 \\
\hline
\end{tabular}

Divers@ Revista Eletrônica Interdisciplinar 
3,5\% dos não identificados entenderam que a carga horária da disciplina ofereceu condições de se comunicarem com uma pessoa surda, mas não contribuiu para que estes tivessem outro olhar sobre as diferenças linguísticas e culturais do mundo surdo. 15,3\% de Letras e 30,7\% de Pedagogia afirmaram que a carga horária da disciplina não ofereceu condições de se comunicarem com uma pessoa surda, mas contribuiu para que estes tivessem outro olhar sobre as diferenças linguísticas e culturais do mundo surdo. Não houve resposta para a alternativa $D$ :A carga horária da disciplina não ofereceu condições de se comunicarem com uma pessoa surda, nem contribuiu para que estes tivessem outro olhar sobre as diferenças linguísticas e culturais do mundo surdo. A participação foi de $100 \%$ na questão.

Existe uma ideia errônea que foi implantada e propagada, classificando o surdo como um ser incapaz e deficiente, desprovido de inteligência, por não fazer uso da comunicação oral da maioria. Fernandes (2011, p. 60; 66) alerta que "o foco da mobilização social dos Surdos é a luta pelo reconhecimento político de sua condição de grupo cultural que representa uma minoria linguística.".

Felipe (2007, p. 45) indica que:

Ser Surdo é saber que pode falar com as mãos e aprender uma língua oral-auditiva através dessa, é conviver com pessoas que, em um universo de barulhos, deparam-se com pessoas que estão percebendo o mundo, principalmente, pela visão, e isso faz com que elas sejam diferentes e não necessariamente deficientes.

Isso significa que quando nos reportamos ao 'sujeito surdo', queremos dizer que este indivíduo é um ser que vive imerso em uma cultura visual, com identidade própria e tem um outro jeito de ver o mundo e de se expressar.

Padden apud Felipe (2007, p. 45) aponta que a cultura de um povo retrata suas práticas e conhecimentos aprendidos e transmitidos na comunicação ou através de hábitos inveterados, sejam eles sua língua, normas, valores, comportamentos, dentre outros. Portanto, a comunidade surda pode ser formada tanto por ouvintes quanto por surdos não culturalmente surdos, e compõe-se de um grupo de pessoas que moram em localização particular e trabalham para alcançar metas comuns compartilhadas por seus membros. Já a cultura da pessoa surda é composta por pessoas que fazem uso de língua de sinais.

Dorziat (2009, p. 25) elucida que as comunidades surdas são um lugar onde há trocas de experiência, de afirmação política, de conquistas e lutas sociais e intensificação de aspirações e necessidades, que "podem vir a desfazer rótulos que só contribuem para a perpetuação de uma visão circunstancial das situações mostradas nas falas dos próprios Surdos.”.

Stroebel (2008, p. 30) complementa que a identidade da cultura se dá paulatinamente, ou seja, não se trata de uma identidade que foi geneticamente adquirida de forma natural.

A partir dos dados inquiridos, notamos que nem todos os graduandos os quais concluíram esta etapa saíram conseguindo se comunicar com uma pessoa surda. O certo é que a disciplina provocou reflexões nos estudantes, os quais estão passando por um processo de construção de aprendizagem. Ter outro olhar sobre as diferenças linguísticas e culturais do mundo surdo requer ter uma nova visão sobre esse alunado. Envolve perceber que ele tem direitos, que merece respeito, atenção e consideração dentro de suas especificidades.

Quando thes foi questionado na questão 4. Sinto-me preparado/a para ministrar conteúdos para um estudante surdo, verificamos que 3,8\% não se expressaram. Apenas 7,6\% de Letras, 3,8\% de Pedagogia e 3,8\% dos não identificados sentem-se aptos para ministrar

\begin{tabular}{c|c|c|c|c}
\hline \multirow{2}{*}{ PERGUNTA } & $4 . \quad$ Sinto-me preparado/a para ministrar conteúdos para & $\begin{array}{c}\text { Participações } \\
\text { um estudante surdo. }\end{array}$ \\
\hline \multicolumn{1}{c|}{ CURSO } & LETRAS (12) & PEDAGOGIA(12) & NÃO IDENT. (2) & UNIVERSO (26) \\
\hline A Sim & 2 & 1 & 1 & 4 \\
\hline B Não & 10 & 10 & 1 & 21 \\
\hline \multicolumn{2}{r}{} \\
\hline
\end{tabular}

Tabela 5 - Opinião sobre Libras - Base de dados: 26 Fonte: A autora

9 - A autora informa que optou pelo uso desse termo porque é empregado pela Organização das Nações Unidas (ONU), no que diz respeito a grupos linguísticos minoritários que encontram discriminação em "comunidades que têm uma língua oficial diversa daquela utilizada pelo grupo em questão.” (FERNANDES, 2011, p. 60)

Vol.6, n.1, p.1-77

I

jan./jun./ 2013

ISSN 1983-8921 
conteúdos para um estudante surdo, ao contrário dos 38,46\% de Letras, 38,4\% de Pedagogia e $3,8 \%$ dos não identificados.

É explícita a situação de insegurança com a qual nos deparamos. Lembramos Mercado (2012, p. 61) apontando que cabe a esses futuros educadores de surdos "desenvolver a alfabetização bilíngue da criança surda, no sentido de tornar a inclusão do surdo na escola regular, satisfatória em seu processo de aquisição do conhecimento.”.

Um profissional inseguro no exercício de sua profissão compromete todo um quadro, sendo que, muitas vezes, os danos são irreparáveis. Reforçamos nossa ideia através de González (2002) apud Martins (2011, p. 53):

No tocante à formação inicial, é necessário que cada profissional em formação seja capaz de: analisar o contexto em que se desenvolve sua atividade e planejá-la, de forma coerente com as mudanças comumente efetivadas na sociedade; empreender um ensino para todos, na etapa da educação obrigatória, atendendo às diferenças individuais, de modo que sejam superadas as desigualdades, mas, ao mesmo tempo, que seja estimulada a diversidade presente nos sujeitos.

A autora ainda comenta que "há necessidade - entre outros aspectos - de um investimento mais substancial na formação dos docentes para atuar, de maneira adequada, frente à diversidade do alunado.” (Idem, 2011, p. 51). Os números destacam a insegurança desses licenciandos. Diante de expressivo quadro, enxergamos aqui a não efetivação da legislação vigente, outrora abordada, que traz sérios questionamentos na educação de surdos: Já que a Resolução CNE/CP n ${ }^{\circ}$ 1/2002 dá autonomia paras as IES organizarem e selecionarem os conteúdos que comporão as matrizes curriculares dos cursos, então qual está sendo o verdadeiro objetivo dessas Instituições ao elencar Libras nas Licenciaturas de Letras e Pedagogia? Para quem/ que esses estudantes estão sendo formados?

Os resultados da questão 5. Ao término da carga horária de Libras ministrada, apontam como está a compreensão da língua do estudante depois de concluir a disciplina. $15,3 \%$ de Letras e 3,8\% de Pedagogia sabem apenas alguns sinais, enquanto $23 \%$ de Letras,
34,6\% de Pedagogia e 7,6\% dos não identificados já conseguem formular algumas frases em Libras. Somente 7,6\% de Letras conseguem expressar fatos do cotidiano em Libras e ninguém alcançou a fluência em língua de sinais. Aquestão ficou com 96,15\% de participações.

\begin{tabular}{|c|c|c|c|c|}
\hline PERGUNTA & Ao térm & $\begin{array}{l}10 \text { da carga horá } \\
\text { ministrada: }\end{array}$ & a de Libras & $\begin{array}{l}\text { Participações } \\
\text { (25) }\end{array}$ \\
\hline CURSO & LETRAS (12) & $\begin{array}{c}\text { PEDAGOGIA } \\
\text { (12) }\end{array}$ & $\begin{array}{c}\text { NÃO } \\
\text { IDENT. (2) }\end{array}$ & $\begin{array}{l}\text { UNIVERSO } \\
(26)\end{array}$ \\
\hline A Sei apenas alguns sinais. & 4 & 1 & 0 & 5 \\
\hline $\begin{array}{l}\text { B Consigo formular algumas frases em } \\
\text { Libras. }\end{array}$ & 6 & 9 & 2 & 17 \\
\hline $\begin{array}{l}\text { C Consigo expressar fatos do meu } \\
\text { cotidiano em Libras. }\end{array}$ & 2 & 0 & 0 & 2 \\
\hline $\begin{array}{l}\text { D Consigo comunicar-me } \\
\text { fluentemente em Libras. }\end{array}$ & 0 & 0 & 0 & 0 \\
\hline
\end{tabular}

A observância na participação dos discentes aqui faz-nos repostarmos ao futuro (momento em que estes protagonizarão suas carreiras).

Dorziat (2009, p. 69) salienta abaixo a importância da interação entre professor e aluno no processo ensino-aprendizagem. E essa inter-relação da qual nos referimos se inicia pela comunicação efetiva entre os atores da educação. Entendemos que a falta e/ou ausência de um vínculo entre professor/aluno tende a comprometer e restringir a aprendizagem.

Certamente o fato de apenas estar em ambiente considerado normal será insuficiente para desenvolver práticas adequadas. É preciso que sejam estabelecidas interações reais professor-aluno, aluno-aluno, conhecimento-aluno e, em consequência, deemse as negociações de sentido de cada realidade. Sem esse critério, estaremos promovendo uma pseudoinclusão.

Mercado (2012, p. 70) expressa a seguinte ideia:

Sabemos que, para desenvolver adequadamente a educação da criança surda, o professor requer muito mais do que conhecimento básico de sinais para a comunicação com o surdo, ou rápidas incursões sobre as especificidades da cultura, 
Face ao exposto, a pergunta que nos advém é: será que um profissional consegue proporcionar a educação de uma criança sem saber como se comunicar com ela, sem compreender seus questionamentos e manifestações, não tendo meios de buscar exemplos, argumentações e conceitos na língua do estudante no momento da mediação de sua aula? Será que o ato de educar resume por si só em formular algumas frases (opção mais respondida pela maioria dos estudantes) e isso basta para que a construção de saberes aconteça?

Apesar de apenas 7,6\% dos entrevistados terem manifestado que teriam condições de expressar fatos de sua rotina em Libras, há unanimidade por parte dos estudantes ao avaliar a disciplina como bastante importante, assim vista na última pergunta do questionário.

Aquestão 6 interpela os participantes, finalizando a atividade de pesquisa: Para minha atuação profissional, considero a disciplina de Libras no meu curso. A participação foi de $100 \%$ e as respostas foram idênticas: todos os estudantes consideram a disciplina de Libras no curso muito importante para a sua atuação profissional. Ninguém a vê como irrelevante ou indiferente.

\begin{tabular}{l|c|c|c|c}
\hline \multicolumn{1}{c|}{ PERGUNTA } & 6. & \multicolumn{2}{c|}{ Para minha atuação profissional, considero a disciplina } & $\begin{array}{c}\text { Participações } \\
\text { de Libras no meu curso: }\end{array}$ \\
\hline \multicolumn{1}{c}{ CURSO } & LETRAS (12) & PEDAGOGIA(12) & NÃO IDENT. (2) & UNIVERSO (26) \\
\hline A Irrelevante & 0 & 0 & 0 & 0 \\
\hline B Muito importante & 12 & 12 & 2 & 26 \\
\hline C Indiferente & 0 & 0 & 0 & 0 \\
\hline \multicolumn{5}{c}{ Tabela 7 - Opinião sobre Libras - Base de dados: 26} \\
Fonte: A autora
\end{tabular}

Com o advento do movimento educacional inclusivo, tratado na Declaração de Salamanca, esses licenciandos, no exercício futuro de sua atuação profissional, a qualquer tempo poderão ser incumbidos de lecionar a alunos que apresentem necessidades educacionais especiais.

Devido a essa demanda em ascensão, os números mostram que todo o público pesquisado reconhece a necessidade do conhecimento de Libras para realizar melhor atendimento ao alunado surdo.

Martins (2011, p. 60) e Mercado (2012, p. 72) também elencam que a formação de professores precisa trajar maior consistência, havendo necessidade de um trabalho adequado frente aos desafios impostos pela sociedade, visando à eliminação de barreiras atitudinais, ainda presentes na sociedade.

\section{Considerações Finais}

É sabido que mediar conhecimentos às crianças trata-se de uma tarefa que deve ser realizada com bastante afinco e convicção. Entendemos que a educação de crianças surdas também demanda larga tenacidade, exigindo esforços de seus educadores.

As informações inquiridas, as leituras realizadas e a participação dos graduandos da Faculdade Estadual de Filosofia, Ciências e Letras de Paranaguá (cursos Pedagogia e Letras), demonstram como tem se delineado a formação desses professores, deflagrando que existem pontos os quais devem ser repensados nas licenciaturas. Assim sendo, sugerimos alguns procedimentos, os quais viabilizarão a atuação desses futuros profissionais: ampliação da carga horária da disciplina de Libras, incluindo conteúdos os quais deem maior sustância à ação docente; desenvolvimento de atividades que proporcionem situação real entre teoria e prática pedagógica, como entrevistas, debates e palestras com outros profissionais da área (surdos e ouvintes); discussão sobre obstáculos encontrados em sala de aula e estratégias para

10 - Resultado da Conferência Mundial de Educação Especial, ocorrida entre 7 e 10 de junho de 1994, cujo foco foi a reafirmação da Educação para Todos. Disponível em

https://www.google.com.br/url?sa=f\&rct=j\&url=http://portal.mec.gov.br/seesp/arquivos/pdf/salamanca.pdf\&q= \&esrc=s\&ei=EClCUcvaMOmCygGrgoHAAQ\&usg=AFQjCNEFnIjo5NDXb9BHmOLh4MaCMYQ1 Kg 
enfrentá-los, estudo de casos, visitas a escolas e comunidades surdas; cumprimento de parte da carga horária do estágio supervisionado em salas de aula com estudantes surdos ou escolas bilíngues; enfim, maior vivência com o povo surdo.

Faz-se mister também ampliar as atividades extracurriculares na área, como congressos, mesas redonda, seminários, cursos, através de parcerias firmadas com Instituições como a Federação Nacional de Educação e Integração dos Surdos (Feneis), Universidade Federal de Santa Catarina (UFSC), dentre outras.

Quando retomamos a ementa do curso, disposta na introdução deste, temos que: "Esta disciplina objetiva desenvolver as habilidades necessárias para a aquisição da LIBRAS (...)”. Grannier (2007, p. 204) explica que a prática de uma língua exige elevado número de horas. Isto significa que o fim maior do texto está longe de ser efetivado. O graduando (mais de $80 \%$ dos pesquisados) está inseguro para ministrar conteúdos para um aluno surdo, quiçá ter conseguido adquirir essa segunda língua (de sinais).

A partir da disciplina de Libras, a formação inicial, neste contexto, vem sendo construída timidamente, contrariando as Diretrizes Curriculares Nacionais para a Formação de Professores da Educação Básica (RESOLUÇÃO CNE/CP 1/2002), que declara que os cursos de licenciaturas devem desenvolver, dentre outras, competências para "o acolhimento e o trato da diversidade".

Indubitavelmente este panorama deve ser revisado: ou a ementa expressa às claras que a disciplina visa ao desenvolvimento de noções para a aquisição da LIBRAS, ${ }^{11}$ ou o conteúdo programático, a carga horária e demais atividades desenvolvidas no campus precisam ter um novo desenho.

Assim como Mercado (2012, p. 70), que ao pesquisar sobre a Disciplina de Libras nos cursos da Universidade Federal do Rio Grande do Norte (UFRN), postula que o total de horas destinado para o desenvolvimento do conteúdo está refletindo na formação desse futuro docente, não permitindo que tenha "conhecimentos satisfatórios para entender a língua, a cultura, as necessidades e especificidades do aluno surdo em seu processo de aprendizagem, a fim de que ocorra, satisfatoriamente, a interação professor/aluno surdo.“, compreendemos que a carga horária da disciplina de Libras atualmente praticada não prepara nem forma profissionais para futuro exercício da profissão no que concerne ao atendimento de sujeitos surdos.

As licenciaturas têm incumbências muito maiores daquelas as quais estão sendo executadas. Cabe a esses cursos, responsáveis pela formação de futuros docentes incumbidos de proporcionar o letramento e alfabetização, disporem uma matriz curricular que condiz com o declarado na Resolução CNE/CP 1/ 2002, como também a ampliação da carga horária, concedendo ao licenciando condições para gozar de uma aprendizagem que "deverá ser orientada pelo princípio metodológico geral, que pode ser traduzido pela ação-reflexão-ação e que aponta a resolução de situações-problema como uma das estratégias didáticas privilegiadas" (BRASIL/ MEC/CNE/CP, 2002, p.3) na educação de surdos.

11 - Opção que compromete um aprendizado voltado ao enfrentamento dos desafios impostos pela sociedade atual 


\section{Referências}

BRASIL. Lei ${ }^{\circ}$ 9.394, de 20 de dezembro de 1996. Estabelece as diretrizes e bases da educação nacional. Diário Oficial [da] República Federativa do Brasil. Brasília, DF, 20 dez. 1996. Disponível em:

<http://bd.camara.gov.br/bd/bitstream/handle/bdcamara/2762/ldb_6ed.pdf?sequence=7 > Acesso em 18 out. 2012.

BRASIL. Conselho Nacional de Educação / Conselho Pleno. Diretrizes Curriculares Nacionais para a Formação de Professores da Educação Básica, em nível superior, curso de licenciatura, graduação plena. Resolução ${ }^{\circ} 01$ de 18 de fevereiro de 2002.

BRASIL. Lei ${ }^{\circ} 10.436$, de 24 de abril de 2002. Dispõe sobre a Língua Brasileira de Sinais Libras - e dá outras providências. Diário Oficial [da] República Federativa do Brasil, Brasília, DF, 25 abr. 2002.

BRASIL. Política Nacional de Educação Especial na Perspectiva Inclusiva. Brasília: MEC/ SEESP, 2008.

BRASIL. Decreto Federal n ${ }^{\circ} 5.626$, de 22 de dezembro de 2005. Regulamenta a Lei ${ }^{\circ}$ 10.436, de 24 de abril de 2002, dispõe sobre a Língua Brasileira de Sinais - Libras. Diário Oficial [da] República Federativa do Brasil. Brasília, DF, 22 dez. 2005. Disponível em: < http://www.planalto.gov.br/ccivil_03/_ato2004-2006/2005/decreto/d5626.htm > Acesso em 18 out. 2012.

DORZIAT, A. O outro da educação: pensando a surdez com base nos temas identidade/ diferença, currículo e inclusão. Petrópolis, RJ: Vozes, 2009. (Educação Inclusiva).

FELIPE, T. A. Libras em contexto. Brasília: MEC/SEESP, 2007.

FERNANDES, S. Educação de surdos. Curitiba: Ibpex, 2011.

GRANNIER, D. M. A jornada lingüística do surdo da creche universidade. In: KLEIMAN, A.B.; CAVALCANTI, M.C. (orgs.). Lingüística aplicada: suas faces e interfaces. Campinas, SP: Mercado de Letras, 2007. p.255-270.

MARTINS, L. de A. R. A visão de licenciandos sobre a formação inicial com vistas à atuação com a diversidade dos alunos. In: CAIADO, K. R. M; JESUS, D. M. de; BAPTISTA, C. R.
Professores e educação especial: formação em foco. Porto Alegre: Mediação, 2011.

MERCADO, E. A. O significado e implicação da inserção de Libras na matriz curricular do curso de Pedagogia. In: ALBRES, N. de A. (org.). Libras em estudo: ensino-aprendizagem. São Paulo: FENEIS, 2012.

PERLIN, G.; STROBEL, K. L. Fundamentos da educação de surdos. Florianópolis: 2008. Apostila do curso de licenciatura/ bacharelado em Letras Libras. Disponível em: < http://pt.scribd.com/doc/4559884/Fundamentos-da-Educacao-dos-Surdos > Acesso em 16 out. 2012.

QUADROS, R. M. de; KARNOPP, L. B. Língua de sinais brasileira: estudos linguísticos. Porto Alegre: Artmed, 2004

QUADROS, R. M. de; SCHMIEDT, M. L. P. Ideias para ensinar português para alunos surdos. Brasília: MEC, SEESP, 2006 . Disponível em: < http://portal.mec.gov.br/seesp/arquivos/pdf/port_surdos.pdf >.Acesso em 10 nov. 2012.

SKLIAR, C. Perspectivas políticas e pedagógicas da educação bilíngue para surdos. In: SILVA, S; VIZIM, M. (orgs.). Educação especial: múltiplas leituras e diferentes significados. Campinas: Mercado de Letras: Associação de Leitura do Brasil, 2001. p. 85-109. (Leituras do Brasil).

STROEBEL, K. L. Reivindicação da comunidade surda brasileira. Brasília/ DF: Setembro Azul, 19 de maio de 2011.

STROBEL, Karin Lilian. Surdos: vestígios culturais não registrados na história Florianópolis, 2008. Tese de Doutorado em Educação. Universidade Federal de Santa Catarina -UFSC.

UNESCO. Declaração de Salamanca. Sobre Princípios, Políticas e Práticas na Área das Necessidades Educativas Especiais. Disponívele m: <http://portal.mec.gov.br/seesp/arquivos/pdf/salamanca.pdf> Acesso em: 14 mar. 2013.

UNIVERSIDADE FEDERAL DO PARANÁ. Setor Litoral. Cursos de graduação. Disponível em: < http://www.litoral.ufpr.br/grad > Acesso em 24 fev. 2013.

WITKOSKI, S. A. Educação de surdos, pelos próprios surdos: uma questão de direitos Curitiba: CRV, 2012. 
ANEXO

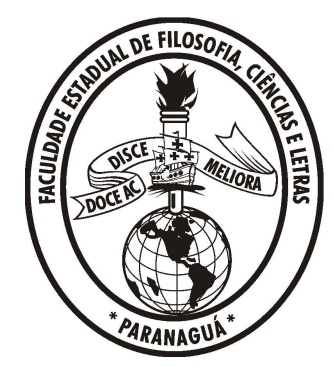

\section{FACULDADE ESTADUAL DE FILOSOFIA,}

CIÊNCIAS E LETRAS DE PARANAGUÁ

Criada por Decreto $\mathrm{n}^{\circ} 4.144$ de agosto de 1956 e autorizada pelo Dec. n $^{\circ} 47.667$ de 19/01/1960

Reconhecida pelo dec. $\mathrm{n}^{\circ} 54.355$ de 30/09/1964

Transformada em Autarquia Estadual conforme Lei no 9.663 de 16/07/91

DEPARTAMENTO: Educação

DISCIPLINA: Língua Brasileira de Sinais - Libras

CARGA HORÁRIA: 68 h/a

PRÉ-REQUISITO: não há

CURSO: Pedagogia

ANO: $2^{\circ}$ ano

ANO LETIVO: 2009

EMENTA

Esta disciplina objetiva desenvolver as habilidades necessárias para a aquisição da LIBRAS - a língua de modalidade visual e gestual das pessoas surdas. Abrange os conteúdos gerais para comunicação visual, baseada em regras gramaticais da Língua de Sinais e da Identidade e Cultura Surda.

CONTEÚDO PROGRAMÁTICO:

- Identificação pessoal;

- Regras de números;

- Operações aritméticas

- Sistema de classificadores em sinais;

- Expressão facial e corporal: incorporação e não incorporação;

- Espaço e tempo: dimensões física e social;

- Sistema de família;

- Aspectos lingǘsticos;

- Processo anafórico;

- Pronomes ocultados

- Níveis de produção de sinais;

- Iconicidade e arbitrariedade;

- Perceber os sinais de onomatopéia (sinais realizados associados com sons);

- Jogos e brincadeiras em sinais;

- Sistema de transcrição de sinais

- Contexto em sinais;

- Os sinais de interdisciplinaridades

- Elementos visuais

- Dialogo cotidiano: (Fazendo um pedido ou situações diversas)

BIBLIOGRAFIA

- FERREIRA BRITO, L. Por uma Gramática de Língua de Sinais. Rio de Janeiro: Tempo Brasileiro, 1995.

- SOUZA, M. Que Palavra que te Falta? São Paulo: 1998.

- SACKS, Oliver. Vendo Vozes-Companhia das Letras. São Paulo, 1998.

- RÓNAI, Escola de Tradutores. Rio de Janeiro: Educom, 1976.

- STROBEL, Karin. As Imagens do outro sobre a Cultura Surda. Editora UFSC. Florianópolis, 2008. 